\title{
"UNICUL LUCRU CAPABIL SĂ SURPRINDĂ UN CRÂMPEI DE VEȘNICIE, ESTE ARTA" FORESTIERA FELTRINELLI, DE JOACHIM WITTSTOCK, TRADUCERE DE MARIA SASS
}

\section{ANA-BLANCA CIOCOI-POP}

Universitatea "Lucian Blaga” Sibiu

Abstract: Joachim Wittstock's novella Forestiera Feltrinelli, translated into Romanian by Maria Sass, appeared under the aegis of the Honterus publishing house in Sibiu, in 2019. Combining present-day economic realities, with a parallelism of temporal planes, and the antonimy between the mythical past and the disillusioning present, Wittstock manages to interweave in his most recent volume social and historical analyses, love stories and subtle eroticism, existentialist concerns and political dimensions. The volume can be regarded as an important contribution to a better relationing of the Romanian readership with German literature in Romania, and to a better understanding of the complex thematic and narrative mechanisms in Joachim Wittstock's works. A fascinating page of the history of Sibiu, of the Romanian Saxons, and of the author's biography, the volume is a succesful and innovative attempt in the landscape of contemporary Romanian and European literature, and its Romanian translation a welcome and necessary initiative in view of a multicultural understanding of the literatures of ethnic minorities in Romania.

Keywords: Forestiera Feltrinelli, Joachim Wittstock, Maria Sass, literary translation, German literature in Romania, Romanian Saxons, documentary literature, Sibiu 
Scriu aceasta recenzie a celui mai recent volum semnat Joachim Wittstock, Forestiera Feltrinelli, apărut sub egida Editurii Honterus, la Sibiu, în anul 2019, în complexa și cuprinzătoarea traducere a Mariei Sass, în timp ce în fundal, posturile naţionale de televiziune și paginile de știri online documentează cel mai recent episod din odiseea defrișărilor ilegale din România: alunecarea de teren din localitatea Azuga, cel mai probabil o consecință a defrișărilor masive, în urma căreia douăzeci de familii au fost evacuate și cursul pârâului Azuga a fost afectat $^{\bigotimes}$. Este una din multele știri pe acest subiect care domină mass media românească de câteva luni. Insă în ciuda semnalelor de alarmă repetate, și a abordării subiectului nu doar de canalele media, ci și de internauți prin intermediul platformelor de social media ca de pildă Facebook, problema rămâne blocată la nivel pur informațional, fără a se fi luat vreo măsură în acest sens. Citesc, deci, povestirea lui Wittstock, și nu pot să nu mă gândesc involuntar la autori ca Orwell, Huxley, sau mai recent, Michel Houellebcq ${ }^{1}$, și prin ei, la rolul adesea profetic al literaturii. Dincolo de orice raționament de tip conspiraționist: știu, oare, scriitori ceva ce noi nu știm? Pot ei (pre)vedea lucruri care scapă ochiului unui simplu muritor? Si de ce, atunci, suntem încă atât de departe de a recunoaște, altfel decât la nivel pur declarativ, acest rol profetic al literaturii? 'Cât de mult se întrepătrund trecutul și viitorul, uneori sub ochii noștri, fără ca noi să realizăm? Și cât de mult imită realitatea ficttiunea, pentru a-l parafraza pe Oscar Wilde?2

Născut la 28 august 1939 în Sibiu, Joachim Wittstock a fost student al Facultății de Filologie din Cluj-Napoca, în cadrul căreia a absolvit Germanistica și Limba și literatura română (1956-1961). După finalizarea studiilor și-a început cariera în învățământ, ca profesor de limba germană în Ćisnădie și Sibiu, a activat apoi ca bibliotecar, iar între anii 1071-1999 a fost angajat al Institutul de Cercetări SocioUmane din Sibiu. Fiu al cunoscutului scriitor de expresie germană din România, Erwin Wittstock (1899-1962), autorul susținea că scrisul ar fi constituit în familia sa o preocupare centrală atât pentru tineri cât şi pentru vârstnici, tatăl său fiind cel ce i-a deschis calea către literaturằ. Aflat astfel în umbra tatălui său, tânărul scriitor și-a lansat volumul de debut, Botenpfeil, doar după vârsta de 33 ani. Á publicat numeroase lucrări în perioada comunistă, cărora li s-au alăturat apoi după 1990 varii

\footnotetext{
1. "Momentul unei alunecări de teren masive în Azuga. 20 de familii, evacuate din locuințe. Râul, acoperit de versant." DIGI 24, 10.04.2020

2. Romanul lui Houellebecq Serotonină, a fost interpretat ca o profeție a mișcării Vestele Galbene în Franța.
} 
volume la edituri din țară și din străinătate. Pentru creația sa Joachim Wittstock a fost distins cu numeroase premii ale Uniunii Scriitorilor, și ale Fundației Germane Schiller din Weimar, premiul Andreas Gryphius, și i s-au oferit distincțiile de Cavaler al Ordinului pentru Merit și titlul de Doctor honoris causa al Universității "Lucian Blaga" din Sibiu.

Asemena personajului din Forestiera Feltrinelli, Luigi di Brunello, Wittstock se reîntoarce prin tematica romanelor la locațiile copilăriei sale, sau, așa cum o spune Maria Sass, la "peisajul transilvănean în care autorul își are rădăcinile și care şi-a pus amprenta asupra sa, fără a se putea vorbi de un "mit trivial legat de locul natal"”’3. Nu întâmplător, autorul isși sub-intitulează povestirea "mit și crâmpeie de realitate". Pe coperta volumului găsim și următoarele clarificări suplimentare: "Dacă autorul ar fi întrebat care aspect din natură l-ar caracteriza ar răspunde: se simte definit mai ales de pădure. Asta se datorează probabil faptului că dincolo de gardul viu al grădinii copilăriei sale brașovene se întindeau dealuri acoperite de livezi și codrii. Ele se prelungiseră parcă în nemărginire și îl ispiteau mereu să le străbată." "You can't go home again" (Nu te poți întoarce acasă) spunea Thomas Wolfe. Cu toate acestea, literatura în totalitatea ei este nimic altceva decât încercarea de a recupera un cămin imaginar. Același lucru poate fi afirmat și despre proza lui Joachim Wittstock, și despre cel mai recent text literar semnat de autor, Forestiera Feltrinelli. Trecutul, am afirmat, se întrepătrunde $\mathrm{cu}$ miticul și imaginarul, fapt consemnat de însuși autor în Notele din finalul volumului: "(...) rememorarea unor destine omenești, m-au determinat să îmbin faptele cu imaginația, folosind foarte liber informații autentice. (...) Încă un indiciu: pentru a mă distanța de mine însumi și a completa realul cu fictivul, am folosit ocazional pseudonime" '. Trecutul este, întotdeauna, în egală măsură realitate și ficțiune. Tot ceea ce putem cuprinde din el sunt, așa cum o spun autorul și traducătoarea, "crâmpeie", fragmente, sclipiri momentane în noianul vremurilor.

Dacă nu te poți reîntoarce acasă niciodată, atunci unicul lucru care îți rămâne este să îți clădești o casă nouă, cât mai asemănătoare celei la care nu mai ai acces. Pentru a realiza acest deziderat este necesară îmbinarea realității cu ficțiunea, rezultatul fiind, așa cum o spune însuși autorul în Prefața sa, un volum de fictiune documentară: "Exploatarea forestieră și fabrica de cherestea din Tălmaciu, nu departe de Defileul Oltului prin Carpații Meridionali... Involuntar pătrund în relatare și

3. Forestiera Feltrinelli, Postfață, 82.

4. Forestiera Feltrinelli, Note, 79. 
momente de istorie economică, date din istoria locală și subiecte de cultură și civilizație. Acest fapt include textul în categoria ficțiunii documentare (Dokufiktion). (...) Aceasta înseamnă că o scriere în proză precum cea care urmează este creată în parte pe baza unor fapte, în sensul a ceea ce poate fi considerat documentat, ceva ce trezește măcar impresia autenticului" ". Interesantă este și remarca autorului, conform căreia "la prelucrarea artistică a faptelor, adaosurile ficționale sunt (...) indispensabile" pentru ca rezultatul să fie unul "întru totul plauzibil”. $\mathrm{Nu}$ poate exista, deci, realitate fără ficțiune - iar acest raționament este unul deosebit de important pentru înțelegerea complexă a povestirii lui Wittstock. Orice rememorare este ficțiune, orice reîntoarcere este ficțiune, și orice realitate este produsul transfigurat al imaginației.

În Postfața volumului, Maria Sass surprinde magistral esența tematică a romanului, de mare actualitate în România: "Deja în această etapă profesională cuvântul cheie, numit în titlu Forestiera Feltrinelli, auzit de protagonist adesea pronunțat, îi stârnește interesul și începe să-i cerceteze istoricul, latura economică, așezarea, în povestire sunt atrase și aspecte de actualitate, mai ales în ceea ce privește defrișarea abuzivă a pădurilor românești, un reproș adus și întreprinderii din Tălmaciu, cum că "familia Feltrinelli ar fi fẳcut, fără reținere, exploatări excesive în pădurile în parte cumpărate, în parte arendate"'”. Romanul lui Wittstock a apărut la finele anului 2019 și pare să prefigureze în mod magistral explozia mediatică pe tema defrișărilor ilegale care a marcat începutul anului 2020 în țara noastră. Ún roman dedicat trecutului, care prefigurează minuțios viitorul? O exprimă elocvent și Maria Sass: "Textul lui Joachim Wittstock este un construct alcătuit minuțios, o transgresiune înscenată literar sub mai multe aspecte: topografie geografică și literară; factual, ficțional, și mitic; suprapunerea instanțelor narative - narator auctorial, personal și însuși autorul cu considerații metatextuale; (auto)biografic și istoric"s'

$\mathrm{Nu}$ pot să nu mă gândesc, citind analiza Mariei Sass referitoare la întrepătrunderea dimensiunilor temporale (și narative) în povestire, la simbolul antic al lui ouroboros - șarpele care își mușcă propria coadă. Originar în iconografia egipteană antică, el este un simbol central în gnosticismul, hermetismul și alchimia vestică, și simbolizează eterna reînnoire ciclică a vieții, morții și renașterii. Carl Gustav Jung spunea

5. Forestiera Feltrinelli, Prefața autorului, 7.

6. Forestiera Feltrinelli, Prefața autorului, 7.

7. Forestiera Feltrinelli, Postfaţă, 85.

8. Forestiera Feltrinelli, Postfaţă, 83. 
despre ouroboros că "simbolizează infinitatea și deplinătatea (...) este un simbol dramatic al integrării și asimilării antagonicului, al umbrei. (...) și un simbol al nemuririi"'. '̂n mod deloc surprinzător, unul din simbolurile cheie ale romanului, pe care traducătoarea le radiografiază cu acribie, este tocmai șarpele: "Prezent în literatură adesea ca simbol negativ, dar și purtător a numeroase valențe simbolice pozitive, şarpele este încărcat în povestirea lui Joachim Wittstock doar cu simbolistică pozitivă, un aspect negativ se ia în calcul doar la finalul povestirii, când se amintește de stema lui Samuel von Brukenthal. Astfel în șarpe sunt întruchipate simbolul vieții și al puterii de tămăduire - amintită fiind și acea componentă din mitologia greco-romană, în care șarpele se transformă în bastonul lui Aesculap, pentru a simboliza "trezirea la viață și știința vindecării”, dar se sugerează și simbolistica infinitului și a nemuririii” ${ }^{\prime \prime}$. Aidoma șarpelui care iși muscă, coada, sugerând infinitul, trecutul mușcă în permanență din viitor, iar viitorul îți extrage seva din trecut, într-o mișcare cỉclică eternă. În romanul lui Wittstock, prezentul și viitorul nu pot exista fără o relaționare permanentă la trecut - iar revizitarea trecutului devine stâlpul narativ al întregului text literar. Bineînțeles, contrastarea trecutului cu prezentul este aproape întotdeauna prilej de durere și dezamăgire, deoarece trecutul devine un tărâm mitic, imaginat mai mult decât real, filtrat prin prisma dorințelor și așteptărilor, și nu neapărat concordant cu realitatea istorică: "Deși venea într-un loc cunoscut, nimic nu i se mai părea la fel, iar o comparație 1914 versus 1920 arăta o decădere totală, chiar și în clădirea unde urma să fie cazat [Luigi di Brunello] câteva zile, totul era părăginit: "tencuiala deteriorată, pardoseala scărilor găurită, o dotare foarte precară a camerelor altădată bogat mobilate"'"11.

Bineînțeles, tema defrișărilor nu este unica temă centrală a volumului. Îmbinând actualitatea economică, cu suprapunerea planurilor temporale, și contrastarea trecutului mitic cu prezentul deziluzionant, Wittstock reușește să îmbine în volumul său analiza socială și istorică, povestea de dragoste și erotismul subtil, problematica existențială şi dimensiunea politică. Revenind la simbolistica şarpelui care își mușcă, coada, am putea afirma că Forestiera Feltrinelli reușește să trateze generalul prin specific, zugrăvind prin prisma aparent restrânsă a minorității germane din Transilvania, problematici general umane, așa cum afirmă și Maria Sass: "Chiar dacă tema centrală este de pe

9. Jung, Collected Works, vol. 14, 513 (traducerea de Ana-Blanca Ciocoi-Pop).

10. Forestiera Feltrinelli, Postafață, 90.

11. Forestriera Feltrinelli, Postfață, 87. 
la jumătatea anilor șaptezeci legată de viaţa sașilor din Transilvania, abordată într-o multitudine de fațete, în care se prezintă și motivul Finis Transilvaniae - cu trimitere la decăderea comunității germane din Transilvania și odată cu aceasta a culturii germane din România -, în cadrul temei sunt dezbătute aspecte istorice, politice, sociale, existențiale, etc. Trebuie însă evidențiat că, dincolo de referirile la comunitatea germană, Joachim Wittstock tratează o problematică general-umană foarte vastă" ${ }^{12}$. În special literatura minorităților a reușit să răspundă acestui deziderat de a reflecta generalul prin specific, de a înscrie literatura memorialistă principiului de bază al geometriei sacre și al hermetismului: "quod est inferius est sicut quod est superius"13. Ceea ce este jos este și sus, ceea ce este particular este și general, ceea ce este individual este și uman. În mod poate paradoxal, modul cel mai eficient de a reflecta aceste problematici general umane este prin problematici specifice. Individualul dă glas în modul cel mai convingător general umanului.

Acest contrast aparent între individ şi umanitate este surprins de către autor în paragraful ce deschide povestirea, și pe care îl vom reproduce integral aici:

Ca profesor nou-angajat în Cisnădie, Ahrnroder era întru totul preocupat să se orienteze în localitate și să cunoască numeroşii oameni, tineri și bătrâni, cu care trebuie să relaționeze un dascăl. Nou-venitul își forma adesea păreri pripite și nu arareori stăruia asupra presupuselor sau chiar îndreptățitelor sale pretenții, adică nu se arătă prea modest, iar uneori nu observa că fandoseala arbitrară, chiar trufașă, nu era decât un mod de a compensa nesiguranța pe care o simțea în sala de clasă, în cancelarie precum și în contactul cu unii oameni din localitate. Se străduia să fie nepărtinitor, voia să pară spontan, dar se trezea în opoziție cu opiniile și obiceiurile încetățenite ale orășelului; rezultatul putea fi un comportament crispat. $^{14}$

A te simți străin și stingher într-un spațiu care ar trebui să îți inspire familiaritate - este o stare de spirit pe care o trăiesc atât Luigi di Brunello cât și Ahrnroder, și am putea afirma că este starea de spirit general umană

12. Forestiera Feltrinelli, Postfață, 82.

13. "Cum este jos așa este și sus”. Traducere în latină de Chrysogonus Polydorus a textului arab al Tabletei de Smarald, una din scrierile centrale ale alchimiștilor europeni.

14. Forestiera Feltrinelli, 9. 
în fața necunoscutului. Luigi se simte străin revizitând locurile cândva cunoscute, deci trecutul, și Ahrnroder vizitând noul său loc de muncă într-un orășel străin, deci viitorul. Ambele dimensiuni temporale sunt cauzatoare de anxietăți, tristețe și sentimente contradictorii. Găsim și aici ecouri ale tematicii timpului ciclic, centrală pentru o bună întelegere a povestirii în ansamblul ei. În acest context, dorim să facem referire la acuratețea cu care Maria Sass, traducătoarea volumului, reușește să capteze legătura complexă dintre simbolistica izvorului (o imagine recurentă în povestire) și imagistica trecutului: "Dincolo de cele expuse mai sus ar mai fi de semnalat că, începând cu Theogonia lui Hesiod și Odele lui Horațiu, izvorul și fântâna sunt simboluri ale inspirației poetice și al legăturii cu trecutul. "Tief ist der Brunnen der Vergangenheit", scria Th.Mann de la început în Iosif și frații săi, făcând trimitere, pe de o parte, la rememorarea tuturor evenimentelor trecute, pe de altă parte, la latura și semnificația mitică a literaturii”"15. Găsim, din nou, aici motivul legăturii cu trecutul. Faptul că izvorul de pe domeniul Brukenthal din Avrig tâsșește din capul unui șarpe face simbolistica și mai evidentă. Atât izvorul, cât și șarpele, sunt simboluri puternice ale trecerii timpului și ale legăturii fluide dintre trecut și viitor. Finalul deschis al povestirii, în care autorul își exprimă speranța ca în viitor izvorul neglijat să fie readus la viață, este nimic altceva decât o ală încercare de unire a dimensiunilor temporale, de întrepătrundere a viitorului cu trecutul. Această întrepătrundere nu este interesantă doar din punct de vedere ideologic, ci și narativ, așa cum subliniază traducătoarea: "Dincolo de frumusețea și profunzimea conținutului povestirii analizate, ceea ce dă satisfacție cercetătorului este arta desăvârșită a narațiunii, realizarea acelui "topos spațio-temporal situat la confluența memoriei și imaginației" 16 .

Cât din memorie este ficțiune, și cât din realitate este fantezie? Acestea sunt întrebările pe care Forestiera Feltrinelli le pune cititorilor săi. Deloc întâmplător, titlul povestirii, care face trimitere la pădure, poartă un dublu sens: pe de o parte, este locul fizic al amintirilor și al trecutului revizitat, pe de altă parte simbolizează hățișurile de nepătruns ale memoriei și ale istoriei, imposibilitatea reîntregirii a ceea ce a trecut, labirintul înșelător al acelei imposibile întoarceri acasă despre care vorbește Wolfe. Fiecare întoarcere acasă este, în final, o întoarcere către sine, așa cum atât de frumos o prezintă Kafka în povestirea sa scurtă Heimkehr (Întoarcerea acasă): "Cu cât mai mult șovăi în fața ușii,

15. Forestiera Feltrinelli, Postfață, 92.

16. Forestiera Feltrinelli, Postfață, 93. 
cu atât mai străin devii. Cum ar fi, dacă acum cineva ar deschide ușa și m-ar întreba ceva. $\mathrm{Nu}$ aș fi eu atunci aidoma cuiva care vrea să își păstreze secretul" 17 . Acel sentiment de a fi străin într-un decor familiar este același pe care îl descrie și Joachim Wittstock, și surprinde distanța temporală și sufletească dintre cel care ai fost și cel care ești, abisul dintre memorie și realitate.

În concluzie, putem afirma că Forestiera Feltrinelli, în traducerea Mariei Sass, reprezintă o contribuție de seamă la apropierea cititorilor români de literatura de expresie germană din România, și la o înțelegere complexă a mecanismelor tematice și narative ale operei lui Joachim Wittstock. O filă fascinantă din istoria Sibiului, a sașilor din România, și din viața autorului, volumul este o încercarea reușită, și inovatoare, în peisajul literaturii contemporane din spațiul românesc și european, iar traducerea în limba româna o inițiativă binevenită și necesară pentru dezvoltarea unei înțelegeri multiculturale a literaturii minorităților din țara noastră. Salutăm apariția volumului în traducere, nu doar ca operă literară și exercițiu de măiestrie în arta traducerii, ci și pentru valoarea sa incontestabilă ca mărturie istorică și socială, ca document viu al punții culturale dintre trecut și viitor.

17. "Je länger man vor der Tür zögert, desto fremder wird man. Wie wäre es, wenn jetzt jemand die Tür öffnete und mich etwas fragte. Wäre ich dann nicht selbst wie einer, der sein Geheimnis wahren will." 